\title{
Corpus Attributes of Online Journals and Websites as Basis for a Free Publication Management Model
}

\author{
${ }^{1}$ Jun S. Camara, PhD, ${ }^{2}$ Cynthia P. Lopez, PhD, ${ }^{3}$ Vemma Mae R. Guinto, ${ }^{4}$ Shella Marie E. Diocares, \\ ${ }^{5}$ Elmer C. Diocares
}

${ }^{1}$ Faculty, Pangasinan State University, Lingayen Campus, Philippines

${ }^{2}$ Vice-President for Research, Innovation and Management Office, Lyceum Northwestern University, Philippines

${ }^{3}$ Faculty, Pangasinan State University, Bayambang Campus, Philippines

${ }^{4}$ Faculty, Pangasinan State University, Lingayen Campus, Philippines

${ }^{5}$ Faculty, Pangasinan State University, Alaminos City Campus, Philippines

Article History: Received: 11 January 2021; Accepted: 27 February 2021; Published online: 5 April 2021

\begin{abstract}
Today, to publish an academic paper requires experience not only in 'doing' the research itself but understanding how it is made available online or in print. This study, an excerpt, has profiled websites and journal articles indexed from the Directory of Open Access Journals during mid-2020 in the field of Science Education, with the end in mind of proposing a publication management model for beginning 'authors'. Using an exploratory mixed method design, this excerpt of the study extracted 185 corpus websites and 103 corpus journal articles from more than 5 million article records of DOAJ. Findings revealed that United States topped the countries with the highest number of corpus and that majority of these journals do not charge submission or article processing charges from authors, yetcontent crawling was observed in most of the journals. Analysis of corpus articles reported sub-sections consistently included in their submission indicative of an international pattern among accepted articles. Recommendations included the proposal to develop a publication management model for beginning 'authors' in state universities and colleges in the Philippines.
\end{abstract}

Keywords: Mixed Method Model, Online Journals, Qualitative, Publication

\section{INTRODUCTION}

Globally speaking, the trend is going for open access publications. Sharing of information within the scientific community is integral to scientific inquiry. This allows other researchers to build upon the research of their colleagues, thereby expanding the frontiers of scientific knowledge. Moreover, scientific data can be reevaluated by the community, which can serve as a feedback mechanism to improve practice and promote the integrity of science. Unfortunately, access to research articles can be blocked by a paywall. This limits access to scholarship not only to researchers but also undergraduate and graduate students who need to read scientific articles for a course or for their theses. Moreover, a researcher cannot ascertain the appropriateness of the article to their study since they only get a glimpse of the article through its title and abstract. With the rising cost of subscription-based journals libraries might not be able to have all the journals they need (Albert, 2006), which adds to the difficulties in libraries amid budget cuts in Philippine state colleges and universities. This proves as a block to scientific knowledge, especially in developing countries such as the Philippines.

However, this issue has been countered for the last three decades with the rise of Open Access (OA). Here, an electronic copy of an article is made accessible to the public via the Internet for free (Albert, 2006). In the "gold" model, instead of the reader paying for access to the article, the author, or their funder or institution, pays a fee to offset publishing costs (Grant-Kels, 2017). Alternatively, the author can self-archive in an online repository, known as the "green" model.

According to Parker (2013), to support OA, scientists most commonly use the argument that sharing data will facilitate scientific advancements and decrease the incidence of repetition of effort. This is because OA allows researchers to quickly disseminate their results to a global audience (Grant-Kels, 2017). Another argument used in support for $\mathrm{OA}$ is that researchers have an accountability to the public, and therefore, the public must have access to research funded by taxpayer money (Grant-Kels, 2017; Parker, 2013). However, in subscription-based models of journal publication, it is the publishers and not researchers who own the copyright, and profit from publiclyfunded research despite academics doing the research itself and peer review for free (Grant-Kels, 2017). 
Yet despite the noble intentions of OA, there are still some ethical issues that surround it which need to be addressed. First, in the "gold" model of OA, researchers pay a fee to offset the cost of producing their articles (Parker, 2013). Although this is beneficial to the public and other researchers, an author from a low-income setting might find it hard to publish due to the costs they must shoulder (Parker, 2013). Also, according to Bealle (2016), this can be exploited by "low-quality publishers" which he called 'predatory publishers,' that try to maximize their profits by publishing more papers at the expense of quality. These publishers can try to lure researchers into publishing using spam e-mail (Bealle, 2016). In fact, Bohannon (2013) created an article on a fictitious medicine that has been accepted by more than half of the publishers he sent it to despite the paper's flaws.

However, some academics have questioned the use of the term "predatory," since authors might be the ones actively seeking these publishers to circumvent the system in an effort to avoid peer review (Memon, 2019). Instead, Memon (2019) proposes the use of the terms "deceptive or parodical journals" and "low quality legitimate journals" and has even created a criteria for differentiating among the two and "high quality open access journals." These criteria, or perhaps, checklists that help identify dodgy journals can instead be used as a guide, rather than a blacklist of potential predatory publishers that Neylon (2017, cited in Smart, 2017) points out to be unreliable and unethical. Or, authors may choose to produce their article with a publisher listed in the Directory of Open Access Journals (DOAJ). This online directory claims to index and "provides access to high-quality, open access, peerreviewed" journals.

Clearly, Philippine Higher Education Institutions (HEIs) can capitalize on the benefits offered by OA. Just like in other countries, Filipino academics are required to publish. However, with the ethical issues associated with models of the OA, a set of guidelines must be crafted on publishing that is contextualized to the Philippine setting. This study can help address this by describing the strategies, trends, and practices in journal management of open access online science journals in Region I. Appropriate changes to practice can be made in institutions based on the results of this study to help Filipino researchers publish their work with credible open access publishers and avoid their articles from being mistrusted due to associations with, or being exploited for financial gain by a questionable publisher.

\section{METHODOLOGY}

Design. This study, an excerpt, employed an exploratory sequential mixed methods research. Qualitative research methodologies are used to explore why or how a phenomenon occurs, to develop a theory, or describe the nature of an individual's experience, while quantitative methodologies address questions about causality, generalizability, or magnitude of effect (Creswell, 2012). As to the corpus, the study is international in scope, and largely abstract in nature. The Directory for Open Access Journals, or DOAJ, has been considered as the primary source of data. As to the validators and staff during data-collection, they are affiliated with the Philippine Association of Research Practitioners, Educators, and Statistical Software Users (PARESSU), Inc duly registered at the Securities and Exchange Commission, Philippines, or SEC.

Corpus Selection. To select online science journals as sources of data in this study, the researcher identified inclusion criteria as minimum requirements. The inclusion criteria as minimum requirements include the following: [1] The journal must be available online during the conduct of the study which is during the summer period of SY 2019-2020; [2]The journal must be open access or that the articles published are freely downloadable, and could be shared; [3] The journal must be in the dissemination of science and science-related research articles, research or review articles; [4] The journal must be found under the Directory of Open Access Journals at the time of data-collection; [5] The language of the journal should be in English; and [6]The journal must have at least one (1) published article online.

Corpus Transcription. In this study, 'document transcript' would refer to each of the sample downloaded articles from each of the open access science journal which successfully passed the inclusion criteria. To select which document transcript would be included as sample, the researcher downloaded the $1^{\text {st }}$ article of the last issue of the last volume published by the online science journal. 


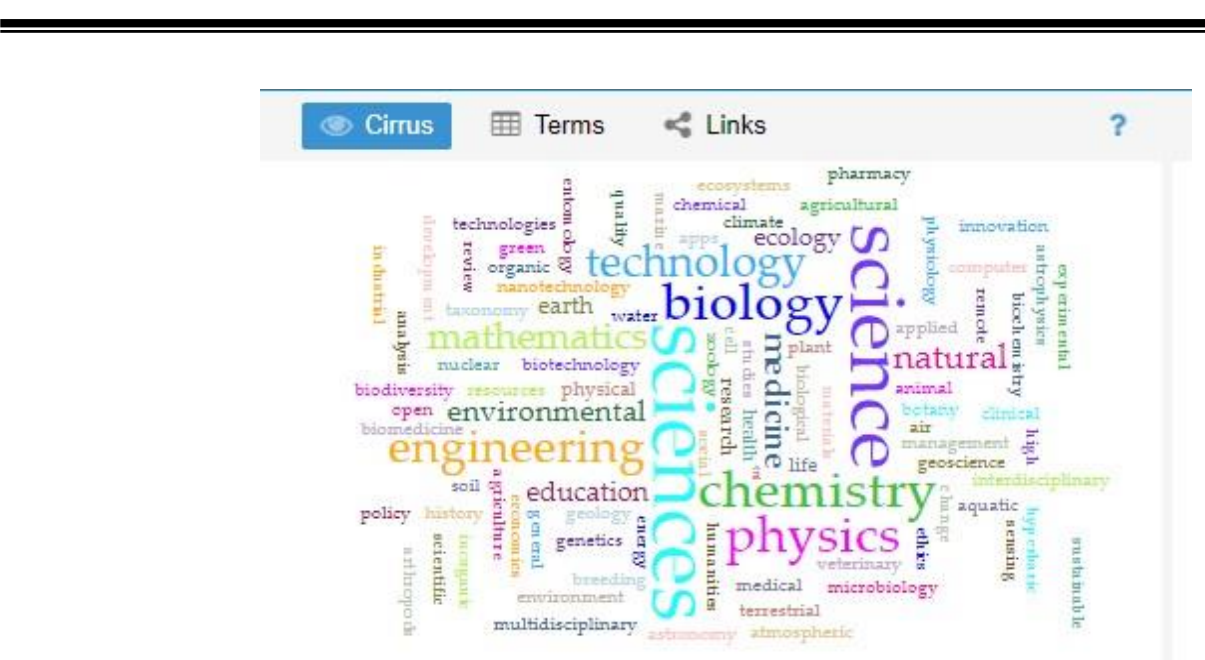

Figure 1. A chart showing the word cloud in voyant tools using the keywords of 185 open access science journals, with top 95 terms.

Figure 1 displays the word cloud provided by voyant tools. The 'Voyant Tools' is a web-based text reading and analysis environment. It is a scholarly project that is designed to facilitate reading and interpretive practices for digital humanities students, and scholar as well as for the general public. When a text is subjected to web-based voyant tools at voyant-tools.org, the software provides a report on analysis of the text, or said to be corpus.

Score Validation. Three (3) validators would be considered for the study who must possess the following minimum requirements as inclusion criteria: [1] Has authored an article published at least in an online Philippine journal; [2] Must have at least 3 citation counts in google scholar; [3] Must have at least an $h$-index of 2 in google scholar; and [4] Must presently be part of an Editorial Team of any local Philippine Journal, preferably a lay-out editor, or copy editor. In this study, evaluation was done properly to avoid bias and prejudice on the part of the researchers and research assistants. To ensure impartiality, several assistants were tapped to perform the following tasks: selecting document websites as corpus, retrieving information from DOAJ, coding variables in SPSS, downloading document article transcripts, validation, and revalidation. To ensure non-communication, research assistants were not informed as to who performed a task prior to them and who will perform a task after them.

\section{RESULTS AND DISCUSSION}

On Profiled WEBSITES. Table 1 displays selected attributes of open access science journal websites indexed in the Directory of Open Access Journals as of mid-2020.

Table 1. Profiled Attributes of the Open Access Science Journal Websites indexed in the Directory of Open Access Journals, or DOAJ, as of mid-2020 ( $n=185)$

\begin{tabular}{llcc}
\hline Profiled Attribute/s & Major Findings & $f$ & $\%$ \\
\hline Country of Publication & United States & 28 & 15.1 \\
\hline Publication Version & Online and Print & 84 & 45.4 \\
\hline Platform & Open Journal System & 68 & 36.8 \\
\hline Article Processing Charges & No & 102 & 55.1 \\
\hline Submission Fee & No & 181 & 97.8 \\
\hline Waiver Policy & No & 138 & 74.6
\end{tabular}




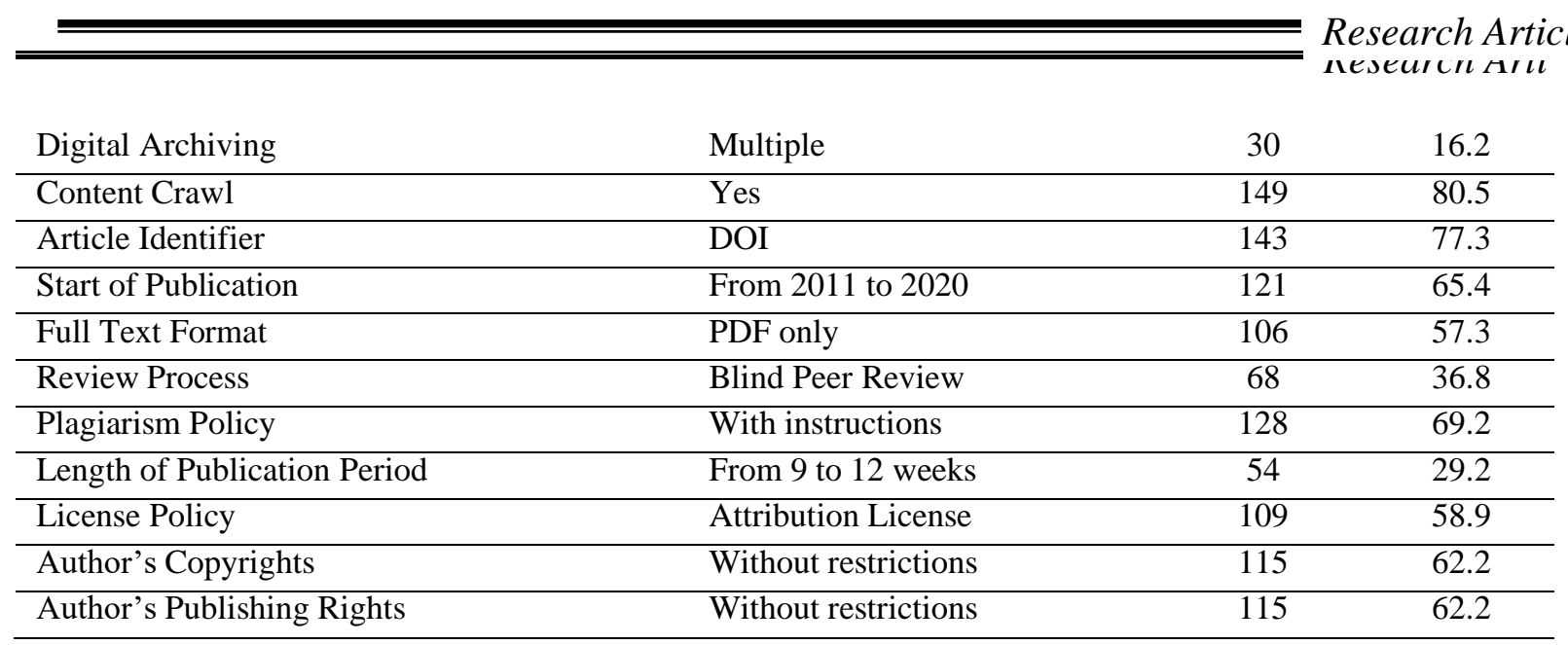

In terms of country of publication, the table shows that United States topped the countries with the highest number of open access science journals indexed in the Directory of Open Access Journals, or DOAJ (28, 15.1\%). In the study of Kumar (2014), United States topped the countries with the highest number of articles published in journals indexed in the Directory of Open Access Journals, or DOAJ, in the field of Environmental Science from 1972-2013. In the study of Camara (2020), United States topped the countries with the highest number of publications in journals indexed in the International Nuclear Information System, or INIS, Database about the Nuclear Science and Technology of the Philippines from 1956 to 2020. This finding could be explained by the strong support of the United States for open access. According to the Global Open Access Portal, the National Institute of Health of the United States mandates the deposit of medical research. It further stated that as of May 2015, USA has 4 funding mandates registered in Roarmap and over 50 institutional mandates at public and private institutions, research universities and liberal arts colleges. Furthermore, in Feb 2013, the US government announced its new OA policy which mandated all publications arising from taxpayer-funded research to be made free to read after a one-year embargo period. This is an expansion on a policy that had till then applied only to the biomedical sciences.

Further, Subbiah (2004) observed some issues and challenges of open access in developing countries. According to him, researchers and institutions in developing countries are the most likely to benefit from the open access initiative. This is not surprising, considering the limited financial resources available in these countries to carter for subscription charges for research and academic journals. With less funding available to libraries and educational institution in the developing world, the benefit of open access cannot be over-emphasized. This unrestricted access made possible by the open access initiative helps researchers in the developing world to undertake and publish their research.

In terms of publication version, the table reflects that the open access science journals in DOAJ publish journal articles in both online and print versions (84, 45.4\%). In an editorial, Travkovski (2018) concluded on the comparison between electronic and printed journals. He stated that as electronic journal usage has increased, users face problems such as searching, accessing, saving and printing. The prevalence of electronic journals or other sources for digital articles is probably one of the main causes for the increase in the amount of readings in all work fields.

In terms of platform, the table evidences that the open access science journals publish their journal articles through Open Journal System as their host, platform or aggregator $(68,36.8 \%)$. In journal publication, Singh and Gupta (2018) emphasized the role of a suitable platform. They said that open access publication cannot be possible without a suitable platform. Most prominent and suitable host for the purpose should be able to manage and publishing scholarly communication. It must be intelligent enough to reduce publishing costs and other traditional processes. The good publication host should be compatible with both the parties, i.e. editors and users. As to OJS, OJS means Open Journal System. Open Journal Systems (OJS) is an open source software application for managing and publishing scholarly journals. Originally developed and released by PKP in 2001 to improve accessto research, it is the most widely used open source journal publishing platform in existence, with over 10,000 journals using it worldwide.

In terms of article processing charges, the table indicates that the open access science journals do not charge any processing fees for article publication $(102,55.1 \%)$. In terms of submission fee, the table displays that the open access science journals do not charge any processing fees for article submission $(181,97.8)$. 
In terms of waiver policy, the table shows that the open access science journals do not have any waiver policy for the payment of article processing charges, for those journals which do ask for APCs from their submitting authors $(138,74.6 \%)$. In his study with special focus on article processing charges and waiver policiesamong authors without paying institution, Burchardt, 2014, claimed that the statement from the world's 27 largestOpen Access publishers reveals through their questionnaires that only four will automatically waive the APC for authors from the poorest developing countries, as identified in the World Bank classification of countries. Half of the publishers indicate that you can apply to have the APC waived. No publisher automatically gives a waiver to the unemployed, pensioners, and so on.

In terms of digital archiving, the table establishes that the open access science journals have multiple digital archiving policies $(30,16.2 \%)$. In terms of content crawl, the table reveals that the open access science journals provide permission for its published content to be crawled (149, 80.5\%). In terms of article identifier, the table shows that the open access science journals employ the use of Digital Object Identifier, or DOI (143, 77.3\%). In terms of start of publication, the table shows that the open access science journals have started their publication during the year 2011 to $2020(121,65.4 \%)$. In terms of full text format, the table reveals that the open access science journals publish their content in Portable Data File format only, or PDF (106, 57.3\%). In terms of review process, the table shows that the open access science journals employ blind peer review in reviewing manuscripts submitted in the journals $(68,36.8 \%)$.

In terms of plagiarism policy, the table reveals that the open access science journals have published instructions in their website on their plagiarism policies $(128,69.2 \%)$. In terms of length of publication period, the table shows that the open access science journals normally accomplish publication from submission to acceptance from 9 to 12 weeks $(54,29.2 \%)$. In terms of license policy, the table shows that the open access science journals employ attribution license as its license agreement and/or policy $(109,58.9 \%)$. In terms of author's copyrights and publishing rights, the table reveals that the open access science journals provide for the author's copyrights and publishing rights and they can use these rights without restrictions from the journals $(115,62.2 \%)$.

On Profiled ARTICLES. Table 2 displays selected attributes of open access science journal articles downloaded from journals indexed in the Directory of Open Access Journals as of mid-2020.

Table 2. Profiled Attributes of the Open Access Science Journal Articles indexed in the Directory of Open Access Journals, or DOAJ, as of mid-2020 ( $n=103)$

\begin{tabular}{llcc}
\hline Profile Attribute & Major Findings & $f$ & $\%$ \\
\hline Corresponding Author & Yes, written & 92 & 89.0 \\
\hline Keywords & Yes, written & 88 & 85.4 \\
\hline Citation Style & Author-Year citation & 73 & 70.9 \\
\hline Journal Link & Yes, written & 71 & 68.9 \\
\hline Submission Date & Yes, written & 85 & 82.5 \\
\hline Revision Date & No, not written & 83 & 80.6 \\
\hline Acceptance Date & Yes, written & 85 & 82.5 \\
\hline Volume Number & Yes, written & 80 & 77.7 \\
\hline Issue Number & Yes, written & 72 & 69.9 \\
\hline Page Numbers & Yes, written & 78 & 75.7 \\
\hline DOI Number & Yes, article identified & 71 & 68.9 \\
\hline License & Yes, agreement written & 59 & 57.3 \\
\hline Journal Logo & Yes, displayed & 63 & 61.2 \\
\hline Introduction & Yes, written & 100 & 97.1 \\
\hline Statement of the Problem & No, not written & 83 & 80.6 \\
\hline Materials and Methods & Yes, written & 75 & 72.8 \\
\hline Discussion of Findings & Yes, written & 82 & 79.6 \\
\hline Conclusions & Yes, written & 71 & 68.9 \\
\hline Recommendations & No, not included & 90 & 87.4 \\
\hline Conflict of Interest & No, not included & 72 & 69.9 \\
\hline Acknowledgments & Yes, included & 69 & 67.0 \\
\hline Research Funding & No, not included & 77 & 74.8 \\
\hline
\end{tabular}




\begin{tabular}{llcc}
\hline Limitations or Notes & No, not included & \multicolumn{2}{c}{ Research Article } \\
\hline Author Profile & No, not written & 25 & 82.5 \\
\hline Author Photo & No, not displayed & 103 & 23.3 \\
\hline
\end{tabular}

Table 2 reveals that the following sub-sections are found written in the coded open access science journal articles: corresponding author $(92,89.0 \%)$ keyword $(88,85.4 \%)$, journal link $(71,68.9 \%)$, submission date $(85$, $82.5 \%)$, acceptance date $(85,82.5 \%)$, volume number $(80,77.7 \%)$, issue number $(72,69.9 \%)$, page number $(78$, $75.7 \%)$, DOI number $(71,68.9 \%)$, license agreement $(59,57.3 \%)$, journal logo $(63,61.2 \%)$, introduction $(100$, $97.1 \%)$, materials and methods $(75,72.8 \%)$, discussion of findings $(82,79.6 \%)$, conclusions $(71,68.9 \%)$, and acknowledgments $(69,67.0 \%)$, and in terms of citation style, author-year citation was employed (73, 70.9\%).

Further, the table reveals that the following sub-sections are not written or not included in the coded open access science journal articles: revision date $(83,80.6 \%)$, statement of the problem $(83,80.6 \%)$, recommendations $(90,87.4 \%)$, conflict of interest $(72,69.9 \%)$, research funding $(77,74.8 \%)$, limitations or notes $(85,82.5 \%)$, author profile $(24,23.3 \%)$ and author photo $(103,100.0 \%)$.

In the study of Camara \& Ventayen (2019) on document transcripts among multidisciplinary journals, they found similar findings and that while the arrangement varies from one journal to another, majority of the transcripts contained the following in the paper itself in the following sequence: 1 . Title of the Multidisciplinary Journal; 2. Journal Volume the paper was published; 3. Journal Issue No the paper was published; 4. Year or series the paper was published; 5. Website the paper could be accessed; 6. Name of the Author; 7. Affiliation of the Author; 8. Email or contact of the Author; 9. Short Bionote of the author; 10. Page number of the paper in the issue; 11. Date paper was received by the editor; 12. Date revised paper was received; 13. Indexing of the journal; 14. Tables and graphs in the body; and 15. (some) Picture of the author.

\section{CONCLUSIONS AND RECOMMENDATIONS}

This study concludes that scholarly publication does not only confine itself with the standard principles and theories spoken by 'experts', but is as well manifested in various websites that contained various journal, and by extension from the published articles that are found therein. Consistency on parameters as found in various journals strongly suggest of common practices in journal management, and common practices in journal writing are manifested as well. The researchers recommend the use of these findings to develop and propose a publication management model that will provide free publication, especially to researchers in the Philippines. The 4-AA Model (Camara, et al., 2021) is recommended as well for integration in the Proposed Publication Model, as well as the monitoring of indicators for Quality Journal Management as given by Oclay, et al, 2020.

\section{BIBLIOGRAPHY}

1. Albert, K. M. (2006). Open access: implications for scholarly publishing and medical libraries. J Med Libr Assoc, 94(3). Retrieved from https://www.ncbi.nlm.nih.gov/pmc/articles/PMC1525322/pdf/i15365050- 094-03-0253.pdf on 7 December 2020.

2. Bealle, J. (2016). Medical publishing and the threat of predatory journals. International Journal of Women's Dermatology, (2), 115-116. DOI: 10.1016/j.ijwd.2016.08.002

3. Bohannon, J. (2013). Who's Afraid of Peer Review? Science, 342 (6154), 60-65. DOI: 10.1126/science.342.6154.60

4. Camara, J. S. (2020). Bibliometric Analysis of Publications on Nuclear Science and Technology of the Philippines from 1956 to 2020. Journal of Critical Reviews, Vol 7, No. 16.

5. Camara, J. S. \& Ventayen, R. J. M. (2020). Publishing Practices Among Senior Multidisciplinary Researchers Using Turnitin.com Originality Reports. ASEAN Multidisciplinary Research Journal. Vol 4, No. 1. Available at journal.paressu.org

6. Camara, J. S. et al. (2020). Management Practices of Pre-College Research as Basis for a Policy Framework. Elementary Education Online. Vol 14 (4)

7. Creswell, J. (2012). Educational research: Planning, conducting, and evaluating quantitative and 
qualitative research (4thed.). Upper Saddle River, NJ: Pearson Education.

8. Grant-Kels (2017). The ethical arguments in support of open access journals. International Journal of Women's Dermatology, (3) 4-5. https://doi.org/10.1016/j.ijwd.2017.01.002

9. Memon, A. R. (2019). Revisiting the Term Predatory Open Access Publishing. Journal of Korean Medical Science, 34(13). https://doi.org/10.3346/jkms.2019.34.e99

10. Neylon, C. (2017). Blacklists are technically infeasible, practically unreliable, and unethical. Period [Web log]. Accessed from http://cameronneylon.net/blog/blacklists-are-technically-infeasiblepractically-unreliable-and-unethical-period/

11. Oclay, A.D., Isla, M. Z. \& Camara, J. S. (2020). Regression Analysis on Publication Views and Downloads of a Philippine Journal and Its Implications to Quality Journal Management and Monitoring. ASEAN Multidisciplinary Research Journal. Vol 4, No. 1. Available at journal.paressu.org

12. Parker, M. (2013). The Ethics of Open Access Publishing. BMC Medical Ethics, 14:16. DOI: 10.1186/1472-6939-14-16.

13. Smart, P. (2017). Predatory journals and research needs. Learned Publishing, 30, 103-105. DOI:10.1002/leap.1101 